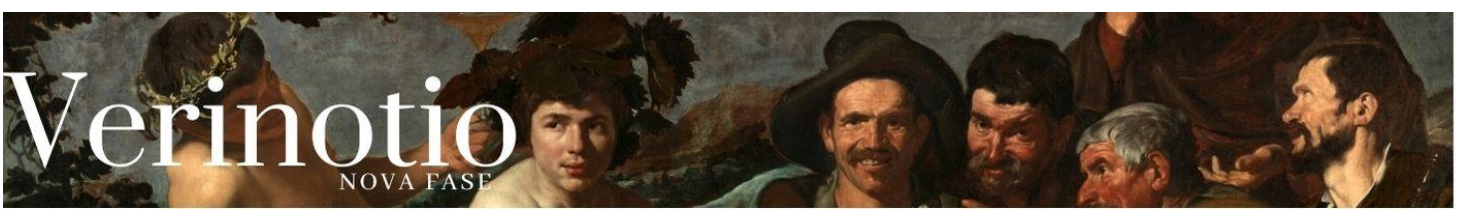

\title{
Apresentação: Heidegger Redivivus
}

\section{Vitor Bartoletti Sartori*}

A presente tradução traz o primeiro momento em que Lukács dedica-se exclusivamente à crítica imanente da filosofia heideggeriana. No texto, ele posicionase diante de Heidegger, em 1949. Neste momento, principalmente na França, como critica o marxista húngaro, já em 1948, em Marxismo ou existencialismo, há certa tentativa por parte da filosofia existencialista de Sartre, Beauvoir e Merleau-Ponty de conciliar-se com o marxismo. Ou seja, a época em que o artigo é escrito remete a certo enfrentamento interno à filosofia marxista, que precisaria decidir sobre a possibilidade de apropriar-se de conceitos típicos de autores, como aqueles mencionados, fortemente inspirados na interpretação (seja ela a mais acertada ou não) das categorias heideggerianas de Ser e tempo. Porém, o cenário é também mais amplo: a posição heideggeriana em resposta à pergunta de Jean Beaufret sobre o humanismo - posição esta analisada por Lukács em Heidegger Redivivus - diz respeito à relação entre a filosofia heideggeriana e o existencialismo. Assim, é preciso perceber que ela não poderia deixar de dizer respeito também ao impacto de $O$ existencialismo é um humanismo, publicado em 1946, por Sartre.

Ou seja, tem-se a tematização de algo que também diz respeito à estrutura interna do próprio existencialismo, bem como às determinações das formações ideais que pretendem partir da tematização desenvolvida por autores como Sartre. Se tanto Heidegger como Lukács enxergam os existencialistas como detratores de suas posições filosóficas, é interessante notar que a maneira pela qual se tem a colocação da questão sobre o humanismo não deixaria de ser vista como equivocada pelos autores em embate.

Heidegger Redivivus, portanto, traz um posicionamento de Lukács neste cenário, em que aquilo que se entende por humanismo, bem como a posição a se adotar diante deste, parecia ser um divisor de águas tanto no que diz respeito ao existencialismo

\footnotetext{
*Professor da UFMG, doutor pela USP e mestre pela PUC SP; e-mail: vitorbsartori@gmail.com.
} 
(Heidegger veio a criticar pesadamente aqueles que 0 associaram a estas tradições) quanto ao se analisar o marxismo, como a polêmica posterior entre Althusser - que em $O$ futuro dura muito tempo confessa ter se inspirado na crítica heideggeriana ao humanismo - e Garaudy iria explicitar mais à frente, principalmente na década de 1960. Só este último embate, que os althusserianos não cansam de trazer à tona, já faria com que fosse necessária a publicação em português do presente texto, que pode lançar luz sobre pontos importantes das questões que vêm enchendo páginas e mais páginas do marxismo althusseriano. Pelo que dizemos, portanto, parece estar claro que é possível dizer que um embate sério dentro do marxismo precisa de um acerto de contas com Heidegger.

O autor, depois de determinado momento, passa a ser um dos filósofos mais influentes e renomados do século XX e não deixa de ser referência obrigatória aos estudiosos da filosofia. Para que tragamos ilustrações importantes deste ponto na tradição marxista, vale mencionar: Marcuse, depois de ter sido orientado por Heidegger, rompe com ele; porém, talvez tenha uma das posições mais tecnofóbicas do círculo dos autores da assim chamada escola de Frankfurt. A crítica à razão (em especial à "razão instrumental") por parte de autores como Adorno e Horkheimer também não deixa de se assemelhar - não obstante as profundas diferenças, e pesadas críticas ao autor de Ser e tempo - com crítica de Heidegger à Ratio. A posição althusseriana contrária ao sujeito e à concepção de Hegel sobre a história, bem como sua crítica ao "humanismo", aproximam-se muito do que Heidegger traz em sua Carta sobre o humanismo, como o Althusser admite no final de sua vida. Temas centrais do mencionado texto de Heidegger são a história, a historiografia, a razão e a técnica e é justamente este texto, ainda hoje muito influente, que Lukács aborda na tradução que aqui trazemos.

Ou seja, caso se queira estudar a filosofia marxista do século $X X$ do ponto de vista da filosofia, não basta que nos atenhamos às querelas sobre a relação entre Marx e Hegel. Elas podem ser importantes em diversos sentidos. Porém, é necessário notar que, posicionando-se diante de condições sociais diferentes daquelas de Marx, e se deparando com formações ideais distintas, o marxismo do século $X X$ - com seus caminhos e descaminhos - precisa ser entendido também em resposta a outros autores, como Heidegger. No caso de Lukács, isto ganha importância tanto porque o autor húngaro viria a desenvolver no final de sua vida uma ontologia que é diametralmente oposta àquela de Ser e tempo, quanto porque ele identifica em 
Heidegger uma figuração típica da filosofia burguesa da história, que viria a fazer escola em nossos dias, por exemplo, nos filósofos pós-estruturalistas. Ou seja, a crítica imanente das formações ideais do século XX - e do século XXI - passa pela apreensão de categorias que são refletidas por Martin Heidegger.

A questão, para Lukács, é que, no autor que critica, e em muitos que se colocam em sua esteira, tais categorias apareceriam de modo distorcido e carentes de toda a historicidade efetiva, como não cansa de se destacar em Heidegger Redivivus. Ou seja, com as formas ideológicas como estas, formas estas pelas quais os indivíduos tomam consciência das contradições sociais, a conformação da sociabilidade burguesa é profundamente estilizada, no limite, estetizada, também é vista de modo rebuscado e "sofisticado", mas vem a se tornar uma espécie de condição humana eterna e mistificada. E, por isto também, de acordo com o raciocínio de Lukács, qualquer tentativa de renascimento do marxismo precisaria passar pela compreensão e pela crítica a estes pontos de vista e a estas concepções de mundo (e não há concepção de mundo inocente), que envolvem autores como Heidegger, mas também - de modo distinto, claro - pensadores anteriores como Nietzsche e contemporâneos, como Wittgenstein, como viria a se preconizar na Destruição da razão e na Ontologia, respectivamente.

Tal aspecto, que diz respeito ao que Lukács chamou de renascimento do marxismo, levam o autor húngaro a temas que são clássicos do pensamento marxista, mas que precisariam ser revistas diante das mudanças na opinião pública burguesa. $O$ autor de Heidegger Redivivus sempre estuda autores não marxistas e se coloca em embates filosóficos profundos, que vão desde as diversas interpretações sobre a obra hegeliana - e para Lukács, até certo ponto, depois de Hegel, e do embate em torno da filosofia do autor da Fenomenologia, não há nada de novo na filosofia burguesa -, até os distintos embates que passam pela influência da obra de Heidegger na politização dos filósofos franceses e na influência que filosofias teológicas como a de Kierkegaard ainda exerce.

Como diz Lukács em suas últimas entrevistas, caso não se quisesse ficar às cegas diante da conformação atual da sociedade capitalista (que aparece em diferentes formas de espelhamento na filosofia que analisa), seria necessário um olhar cuidadoso, por exemplo, diante de temáticas como a da religião. Segundo o autor de Para uma ontologia do ser social, o renascimento do marxismo tem como suposto a superação 
da crítica à religião que se coloca em meados do século XIX (em Fauerbach, por exemplo), de modo a se abranger seja o ateísmo religioso de um Schopenhauer, seja o desespero de um Kierkegaard; e é interessante notar que o marxista húngaro identifica tanto este desespero kierkegaardiano quanto o ateísmo religioso na filosofia de Martin Heidegger anterior e posterior à II Guerra Mundial. Assim, desenvolver o marxismo de modo minimamente digno pressupõe a capacidade de entender e de realizar uma crítica imanente às formações ideais como as de Heidegger, e daqueles que partem das categorias de sua filosofia. Ao contrário do diálogo de Sartre com as categorias do autor de Ser e tempo, como "projeto" e "derrelição" - como colocado em Sobre a questão de método, mas também na Crítica da razão dialética - Lukács critica de modo duro tanto o pensamento heideggeriano quanto a função social dele, que, em um primeiro momento, teria preparado o terreno, mesmo que de modo indireto, para a atmosfera intelectual em que floresce o fascismo e que, diz nosso autor, poderia servir de base - como efetivamente serviu - para a formação de uma visão de mundo baseada na crítica aos sintomas da vida cotidiana burguesa, de um lado e, doutro, na aceitação dos pressupostos histórico-sociais da produção capitalista.

Esta colocação da questão por nossa parte, porém, seria um pouco unilateral. Por enquanto, somente destacamos a importância do embate lukácsiano para que o marxismo pudesse fincar seus pés no século XX e no presente. Em Marxismo ou existencialismo, há uma tentativa, por parte de Lukács, de mostrar a incongruência das tentativas daqueles próximos a Sartre em conciliar categorias que advém da ontologia heideggeriana com o marxismo. Porém, é interessante notar que, ao criticar a Carta sobre o humanismo de Heidegger, o pensador húngaro se depara com uma situação sui generis. ele não julga os existencialistas coerentes com o marxismo, certamente. Porém, também percebe que Heidegger não acredita que eles consigam compreender sua ontologia fundamental. E mais: o autor de Ser e tempo procura demonstrar que a posição que defendia em sua obra magna já estaria ultrapassada. E, assim, o filósofo alemão está a criticar as consequências e as interpretações de sua obra pregressa. E, diante disso, Lukács vai se posicionar. E ele, assim, percebe que as suas investigações iniciadas na década de 1930 e que se colocam em sua crítica ao irracionalismo precisariam ser, no mínimo, complementadas. Os elementos basilares da estrutura da sociedade capitalista teriam se transformado e, com isto, também teriam passado por modificações as funções e as estruturas do pensamento burguês. Heidegger Redivivus, assim, testemunha, ao mesmo tempo, uma continuidade: segundo Lukács, as bases da 
filosofia de Heidegger anteriores e posteriores à derrocada do nazifascismo não teriam se modificado substancialmente. Porém, o autor de Ser e tempo procura se desvencilhar das consequências sociais de sua filosofia e, em textos como sua Carta sobre o humanismo, arrebanha seguidores. E este fenômeno precisaria ser explanado, compreendido e combatido.

Talvez, juntamente com Hegel, o autor de Ser e tempo seja o autor burguês diante do qual Lukács se deparou mais vezes. Mesmo que, como mostrou Tertulian, tenha havido embates importantes do marxista húngaro com Adorno, Brecht, Hartmann e Bloch, por exemplo, Heidegger é dos autores mais criticados. E isto faz com que seja preciso enxergar, mesmo que rapidamente, como a crítica a Heidegger ganha progressivamente mais força no autor de Para uma ontologia do ser social.

Em a Destruição da razão, publicado em 1954, mas escrito entre as décadas de 1930-1940, o autor húngaro critica Heidegger e Jaspers como filósofos do momento pré-fascista. No que se nota dois importantes aspectos: o primeiro deles é que Martin Heidegger, ao contrário de Schelling, Schopenhauer, Kierkegaard e outros não mereceu por parte do autor húngaro um tratamento autônomo. O segundo fato é: mesmo que Heidegger tenha sido filiado ao partido nazista e mesmo que tenha defendido posições explicitamente elogiosas ao nacional-socialismo na década de 1930, Lukács - ao contrário de Adorno, por exemplo - não diz que a filosofia heideggeriana é fascista ou nazista. Antes, ele analisa como que uma teoria de linguagem bastante árida poderia ter preparado o terreno para a angústia e o desespero que seriam as disposições afetivas mais caras à concepção do mundo nacional-socialista. Em Marxismo ou existencialismo, por sua vez, tem-se a análise do existencialismo. A confluência entre a luta contra ocupação nazifascista na França, a interpretação de Ser e tempo de Heidegger e uma posição à esquerda - mas não ao ponto de vista da classe trabalhadora - teriam trazido as condições para o desenvolvimento do existencialismo, e da importância da categoria da derrelição neste pensamento como um índice de suas limitações. Assim, Heidegger aparece na obra de 1948 reflexamente, explicitando-se como alvo central somente em 1949, em Heidegger Redivivus. O autor, que seria tratado posteriormente em Para uma ontologia do ser social, passa a ser visto como alguém essencial para a filosofia burguesa e, com isto, a crítica a ele, aos olhos de Lukács, passa a adquirir uma importância crescente. Pode-se mesmo dizer que a ontologia lukácsiana debate com o autor de Ser e tempo porque é diametralmente a ela em seus pontos basilares, tratados no presente texto. 
Lukács passa crescentemente a remeter às insuficiências da crítica heideggeriana à opinião pública e à democracia (tanto presentes na descrição do autor alemão do "impessoal" quanto nas suas posições mais recentes); e também acontece porque seria preciso compreender as continuidades e descontinuidades do pensamento burguês analisado em $\boldsymbol{A}$ destruição da razão e aquele que se coloca no momento posterior à II Guerra Mundial, momento este em que o nazismo, e aqueles que o apoiaram, passam a ser vistos com certo descrédito. Ou seja, Heidegger Redivivus é, ao mesmo tempo, tanto uma crítica a uma formação ideal que fora e foi influente quanto uma tentativa de atualizar a crítica marxista diante de problemas que se apresentam depois da derrota do nazifascismo em uma situação na qual o capitalismo parece ter outra face. Também se tem neste texto uma temática importante a toda ontologia e que diz respeito à relação entre ser e ente.

Segundo Lukács, a faceta nova do capitalismo apareceria (de modo invertido) tanto nas obras econômicas de um Galbraith, na sociologia de um Wright Mills quanto na filosofia de Heidegger e de outros (somente para exemplificamos os autores aqui). No caso do autor da Carta sobre o humanismo, a angústia de outrora, bem como o apelo a uma ontologia fundamental saem de cena, de modo que aquelas disposições afetivas mais propícias ao desenvolvimento de uma visão de mundo compatível com o fascismo e com o nazismo são tiradas de cena. Lukács, deste modo, admite uma mudança de tom na filosofia heideggeriana e enxerga o abandono das pretensões de uma ontologia fundamental como uma tentativa - subjetivamente mais ou menos sincera, não é este o foco - de voltar-se contra a função social que o pensamento do ser heideggeriano teria exercido. Ocorre, porém, que as determinações da formação ideal do autor alemão permanecem ligadas, de um lado, a uma crítica romântica ao capitalismo, doutro, na busca de uma espécie de terceira via diante das questões essenciais à sociedade capitalista.

O autor da Ontologia critica profundamente Heidegger em sua posição segundo a qual materialismo e idealismo seriam igualmente unilaterais, opõe-se também a abordagem heideggeriana da historicidade e da atividade humana. Lukács diz que a teoria que aborda acerta na crítica de alguns sintomas até certo ponto - como por exemplo na crítica à opinião pública burguesa. Porém, ao invés de se ter uma tentativa de se suprimir os elementos basilares da sociabilidade burguesa, também em suas posições sobre a democracia, sobre o progresso e sobre a história, Heidegger tenta assumir uma espécie de terceira via. E isto somente poderia ser realizado de modo 
profundamente mistificado. A questão importante sobre o ponto de vista de Lukács é que se explica como que tal postura do autor alemão não é um elemento acidental e casual de sua filosofia: é algo basilar e se encontra, por exemplo, na oposição e na muralha chinesa que se coloca de um lado, entre o ser, doutro, entre os entes. Tal aspecto, que configura a chamada "diferença ontológica", e remete ao "esquecimento do ser", ao apelo aos "eventos" da "história do ser" e àquilo "primordial", leva a uma forma renovada de idealismo subjetivo.

E tal qual no embate com a filosofia hegeliana nos meados do século XIX, bem como no final do XIX e no começo do século XX, um elemento importante remete à crítica à religião. Se em um primeiro momento tem-se uma crítica a Hegel pela imanência de sua concepção de história, depois, volta-se diretamente contra a pretensão de uma compreensão histórica no sentido objetivo e, depois, o embate com aqueles que se opuseram a Hegel de modo consequente - e de modo materialista torna-se inevitável. Expliquemos melhor: um autor como Schopenhauer - mas também Kierkegaard - critica o pensamento hegeliano com certa filosofia da história que é saudosa quanto à influência e a função que a religião costumava exercer; Nietzsche, por sua vez, em um momento posterior, em que o imperialismo já se implementa a passos largos, adota uma posição ateia, porém - politicamente - oposta a de Hegel: o último é alguém que prima pela racionalidade do Estado na reconciliação das oposições da sociedade burguesa; o primeiro é um crítico do progresso, da democracia e vem a adotar aquilo de mais bestial do capitalismo como base de sua crítica ao cristianismo. Heidegger, por sua vez, ataca o pensamento hegeliano como uma espécie de onto-teologia e, tanto em Ser e tempo, quanto na Carta sobre o humanismo, traz por central a cisão entre ser e ente, que, segundo Lukács, não pode deixar de remeter a uma espécie de secularização da oposição teológica entre criador e criatura. Um aspecto importante sobre o texto heideggeriano que o marxista húngaro critica é: Heidegger vem a reconhecer a importância da obra de Marx no que diz respeito à história e à experiência do estranhamento no mundo moderno.

Com isto, aparentemente, o autor de Ser e tempo estaria se aproximando de uma concepção objetiva - e não subjetivista, como a de Bergson, por exemplo - de tempo e de história. Ou seja, parece que as pretensões dos filósofos existencialistas, bem como o ímpeto inicial do Marcuse de Materialismo e existência (de aproximar o marxismo da filosofia heideggeriana) estariam em um terreno fértil. Porém, segundo Lukács, seria justamente 0 oposto que ocorreria: as raízes teológicas e 
kierkegaardianas do pensamento de Heidegger seriam mais do que presentes, tendose na oposição entre história e historicidade - correlacionada de modo mediado à oposição entre ente e ser - algo que afasta de modo absoluto as relações sociais e reais. E, assim, tem-se uma pseudo-objetividade, bem como um tratamento a-histórico e mistificado da história. $O$ modo pelo qual se coloca a terceira via heideggeriana levaria - para que se use a dicção de $A$ destruição da razão - a uma espécie de apologia indireta do capitalismo. $E$, assim, haveria razões para que a influência das posições do autor fosse grande. E mais: aqueles que pretendessem apropriar-se das categorias heideggerianas para a reflexão crítica estariam em meio a uma espécie renovada de irracionalismo, que ainda poderia vir a formar, em um futuro mais ou menos próximo, elementos basilares de uma concepção de mundo perigosa e inelutavelmente apologética diante das estruturas da sociedade capitalista.

Hoje, em um momento em que autores como Foucault, explicitamente influenciados por Nietzsche, bem como por Heidegger, são essenciais para o assim chamado pensamento crítico, o presente texto pode trazer elementos importantes para reflexão. Isto se dá até mesmo porque, se é verdade o que diz Lukács, as categorias que critica - e que hoje são lugares comuns na filosofia - não deixam de ter uma origem teológica. Ou seja, Marx criticou os filósofos por somente interpretarem o mundo de diferentes maneiras; Lukács, por sua vez, vê como a realidade objetiva e o mundo se tornam pseudo-objetividades na filosofia burguesa. E o pensamento "crítico" - não se pode nem mais falar "progressista", pois a noção de progresso parece ser um palavrão... - não deixa de se aproximar, cada vez mais, de uma posição relativista e que se esquiva da apreensão reta do real. Sequer se interpreta o mundo; transformálo substancialmente, assim, é impossível. O presente texto, objeto de tradução, procura dar passos no sentido de um embate ideológico essencial ao tempo de Lukács, e ao nosso.

\section{Como citar:}

SARTORI, Vitor Bartoletti. Apresentação: Heidegger Redivivus. Verinotio, Rio das Ostras, v. 27, n. 1, pp. 40-47, jan./jun 2021. 